\title{
A forma simbólica da modernidade
}

Cecilia Marks ${ }^{I}$

[0 MA dialética de perdas e ganhos: assim Franco Moretti introduz sua tese de o romance de formação ser a forma simbólica da modernidade. "Perdi minha subjetividade, mas encontrei um mundo, disse Goethe a propósito da viagem à Itália $[. .$.$] : a vida ofereceu menos$ do que o esperado - porém ofereceu algo a mais, e inesperado" (p.11). Teórico que cunhou o conceito de "distant reading" em contraposição à prática da "close reading" - interpretação rente ao texto que se consolidou ao longo do século XX -, Moretti propõe em $O$ romance de formação manter um olhar distanciado das obras em si para as analisar como representantes de seus respectivos contextos e momentos históricos. Assim, ao abrir mão da leitura imanente para alçar voo e alcançar uma visão extensiva, é dada a possibilidade de estabelecer conexões de enredos e personagens com movimentos sociais que abalaram a dinâmica das relações entre indivíduo e sociedade, abarcando desde aspectos da vida pessoal e cotidiana até a esfera pública e política.

Para desenvolver sua argumentação, o ensaísta transita por um extenso arco de ideias, dialoga com diversas linhas de pensamento, contestando-as ou embasando seu raciocínio - de teóricos como Lukács, Bakhtin, Adorno e Barthes a filósofos e historiadores como Hegel, Tocqueville, Burckhardt e Habermas, além de Freud e Darwin, entre outros. Mesmo assim, chega a uma amarração coesa, embora algumas vezes constranja o leitor a uma dispersão de propósitos. Essa característica da obra, publicada originalmente em 1986, portanto antes de Moretti desenvolver sua metodologia pluridisciplinar para estudar a história da literatura, demonstra que ali já germinavam conceitos que o autor expandiu posteriormente.

De acordo com Mikhail Bakhtin $(2010$, p.121), graças à sua capacidade de renovação permanente, o gênero literário "sempre é e não é o mesmo, sempre é novo e velho ao mesmo tempo. O gênero renasce e se renova em cada nova etapa do desenvolvimento da literatura e em cada obra individual de um dado gênero". No caso do romance de formação, essa passagem é bem marcada por um momento histórico definido e por uma obra específica.

Moretti considera o romance de formação a forma simbólica e hegemônica da modernidade em decorrência das grandes mudanças sociais e econômicas provocadas pela dupla revolução, a industrial e a burguesa. Organizado em quatro grandes blocos, que por sua vez separam-se em capítulos, esses divididos em vários subtítulos instigantes, numa estrutura que remete ao formato de árvore, o livro compreende um período de pouco mais de um século, entre o surgimento do paradigmático $O s$ anos de aprendizado de Wilhelm Meister, de Goethe, publicado em 1795-1796, e o de algumas obras modernistas do início do século XX, até 1914 - essas abordadas em um ensaio adicional.

Uma vez que a definição de romance de formação tornou-se bastante elástica e abrangente, Moretti opta por utilizar o termo original Bildungsroman apenas 
para o romance de Goethe e Orgulho e preconceito, de Jane Austen, os quais considera tradicionais. Os demais títulos do corpus são designados genericamente romance de formação. A apreciação dos dois livros citados conduz a parte inicial do estudo, fincando as bases da argumentação. Nessa escolha também se fundamenta a diferença estabelecida pelo autor entre os movimentos revolucionários e as transformações sociais ocorridas na Alemanha e na Inglaterra, de um lado, e na França, de outro, com seus respectivos reflexos nas obras analisadas e emanações por estas provocadas.

No Bildungsroman tradicional, o protagonista é jovem e culto, em busca de um sentido para a vida. Suas aspirações chegam a ser experimentadas, mas não se efetivam de fato, pois ao final da trajetória ele as abandona em prol de outras vivências, que o encaminham para a conformidade ao mundo e à realidade, harmonizando-se o herói com a sociedade para a qual se formou durante sua jornada rumo à maturidade. Aqui, fica implícito o já mencionado aparato da troca, tão caro ao pensamento burguês.

Assim, para Moretti, a juventude é a imagem que reflete a configuração social, econômica e histórica da modernidade, adquirindo centralidade simbólica por "acentuar seu dinamismo e instabilidade" (p.30). Se no Bildungsroman é permitida à irrequieta interioridade juvenil explorar o espaço social, esse processo de aprendizagem se conclui de maneira harmoniosa sem gerar frustrações, pois a internalização de valores ocorre de maneira a cumprir o que Moretti aponta como o "paradigma ideal da socialização moderna: desejo fazer aquilo que, de todo modo, deveria ter feito" (p.50). A individualidade é a força centrípeta da narrativa, que deságua em uma vida cotidiana equilibrada e estática, diga-se que almejada e plena, embora exteriormente a modernidade siga em progressão contínua - "velocífera", ' numa formulação de Goethe. Nesse sentido, a formação moderna não se dá abruptamente, como um rito iniciático, mas é uma construção significativa visando a uma finalidade.

Isso posto, é preciso frisar que a juventude não perdura para sempre, é passageira, e acaba por trair seus princípios. Sob esse aspecto, o autor salienta as diferenças entre a forma simbólica romance de formação na Alemanha e Inglaterra - onde atuava para evitar os “efeitos irreversíveis" da Revolução Francesa, segundo Moretti (p.123) ${ }^{2}$ em comparação com a França e a Rússia. No Bildungsroman tradicional há uma condução teleológica, que encontra o equilíbrio, a conciliação de interesses das duas classes hegemônicas - a decadente aristocracia e a emergente burguesia. Já nos romances franceses e russos apresentados na segunda parte do livro, a característica é de ruptura, de uma juventude desencantada com os valores revolucionários, que, de resto, compõem um ideário professado mas dificilmente praticado. Mesmo assim, o protagonista de $O$ vermelho e o negro, de Stendhal, não quer trair suas convicções nem renunciar à busca do "sentido da vida", não pretende firmar um compromisso com o sistema. Ao contrário das primeiras, essas narrativas não se fecham nem correm para um final harmonioso, pois não há destino alternativo, senão a morte, a loucura, o desterro, para esses tipos condenados pela ordem social por não abdicarem dos ideais juvenis.

Moretti ilumina com perspicácia o paradoxal conflito entre liberdade e au- 
todeterminação - uma das bandeiras da Revolução Francesa e que se encontra no cerne da modernidade - e os limites impostos pelo próprio capitalismo visando à conformidade e adequação ao modo de produção. Ou seja, o indivíduo moderno é livre, desde que adequadamente socializado/formado para atender às necessidades do sistema - "Em outras palavras, é preciso renunciar a ser 'moderno' ou renunciar a ser "indivíduo'” (p.272). Essa condição sine qua non, conforme Moretti, remete à teoria evolucionista de Darwin, tão cara ao autor, de que sobrevive o que melhor se adapta e não o mais forte. Por outro lado, nessa nova ordem a humanidade se viu "fadada" à liberdade, pois, ao romperem-se as estruturas de subserviência, a liberdade pode ter se tornado um fardo cansativo e doloroso, resultando em medo e solidão (p.113).

$O$ romance de formação se estrutura sobre essas “drásticas antíteses” (p.31) e, justamente pelo seu caráter contraditório, tornou-se a forma simbólica da modernidade; por ser tão paradoxal quanto a cultura moderna, que exige a coexistência de valores opostos para se manter e se reproduzir. Por sua flexibilidade, ecletismo e capacidade de adaptação, o romance de formação superou outras formas narrativas - romance histórico, epistolar, alegórico, satírico, Künstlerroman -, que seguem modelos mais rígidos. "E vice-versa, naturalmente: quanto mais uma forma foi capaz de flexibilidade e compromisso, melhor pôde governar-se no turbilhão sem síntese da história moderna" (p.36).

Diferentes dos heróis integrados do Bildungsroman, a personificação de sujeitos cindidos, fragmentados e incoerentes, trilhando caminhos sinuosos e instáveis, sem uma finalidade determi- nada, faz surgir, nos romances franceses do século XIX, "novas constantes estruturais [que] colocam, por assim dizer, o romance de formação em sintonia com seu tempo" (p.14l). Neles, os processos de individualização e de socialização são incompatíveis, e Moretti enumera algumas das principais antíteses recorrentes em romances pertencentes às duas correntes: casamento versus adultério; felicidade versus liberdade; individualidade versus perda da identidade.

Contudo, enquanto em Stendhal o sentimento de desilusão se impõe, em Balzac, Lucien de Rubempré é o "herói da mobilidade social" (p.208), imediatista e pragmático. $\mathrm{Na}$ Comédia Humana as contradições já se mostram assimiladas e o motor do progresso e do sucesso pessoal é incorporado à narrativa, que desvela a relatividade dos valores desse modelo social, em que a moda e o consumo pautam as relações de maneira superficial e efêmera. Aqui, a narrativa da juventude coloca "em relevo a força desumana e indiferente do novo mundo, que reconstrói - como se fosse uma autópsia - a partir das feridas infligidas ao indivíduo" (p.254).

No bloco final do livro, Moretti se detém em particularidades observadas na Inglaterra - "única nação europeia em que 1789 não se afigurou como o ano zero da modernidade" (p.277) -, caracterizada por estabilidade de valores, firme regulação jurídica, hierarquia e conformismo. No cânone literário inglês do período, o autor observa uma desvalorização da juventude e, antes, um desígnio pela manutenção de escolhas feitas pelo herói na infância, o que denomina de "romance de conservação" (p.279) mais do que de formação. Assim, essas narrativas se aproximam 
dos contos de fada, cuja estrutura é de polarização e qualquer ambiguidade é dissipada no final. Os personagens são pautados por uma espécie de taxonomia e dependem de coincidências narrativas para promoverem o andamento do enredo (p.295), prática que levará, de acordo com Moretti, à forte tradição inglesa de romances de terror e de suspense. O autor, entretanto, faz questão de indicar as exceções: “George Eliot... e tudo muda. Junto a Jane Austen ela é a única escritora que soube renunciar ao modelo do conto de fadas judiciário e se mediu com a problemática europeia do romance de formação" (p.324).

A análise das transformações ocorridas no romance de formação desde o seu surgimento é complementada por considerações sobre um pequeno rol de romances modernistas, de Conrad, Mann, Musel, Walser, Rilke e Kafka. Moretti constata que essas obras-primas não iniciaram uma nova etapa na história do romance de formação europeu, mas sim a encerraram de vez. Isso porque, nessas narrativas - inseridas em uma realidade moderna já consolidada - o protagonismo do indivíduo é soterrado pelas instituições, essas sim instrumentos deliberados de coerção. Esse é "o mundo do romance de formação tardio", que repercute ainda hoje.

Tais reflexões constam de um ensaio publicado em 1990, incorporado ao livro, assim como o prefácio autocrítico do autor, redigido em 1999, em que esse aponta as limitações de ordem geográfica, social e histórica da obra e esclarece alguns caminhos teóricos percorridos posteriormente. Outros aspectos positivos são as referências contidas em notas de rodapé remeterem a edições acessíveis ao leitor brasileiro, o índice onomástico e a lista de edições nacionais do corpus estudado, embora alguns títulos, tanto dos romances analisados como da bibliografia teórica, disponham de edições e traduções mais recentes e atualizadas.

A publicação de $O$ romance de formação reveste-se de relevância, pois a obra pode dialogar com uma tradição recente, porém consistente, que se estabeleceu no país a partir dos anos 1990, com estudos como O cânone mínimo, de Wilma Maas, e Labirintos da aprendizagem, de Marcus Mazzari, autor com quem divido a organização de Romance de formação - Caminhos e descaminhos do herói (no prelo), volume composto por 26 ensaios de diversos pesquisadores, abordando obras de diferentes origens e períodos.

\section{Notas}

1 Trata-se de uma "referência alegórica ao incipiente ritmo 'velocífero' (neologismo criado por Goethe) da modernidade e ao seu caráter autônomo" (Mazzari, 2019).

2 Nesse sentido, o autor parece desprezar o tom irônico insinuado por Goethe em Os anos de aprendizado de Wilhelm Meister, conforme aponta Mazzari (2018): "Goethe designou Wilhelm Meister como 'pobre cachorro' numa conversa registrada pelo chanceler von Müller em janeiro de 1821: 'mas apenas com personagens como essas que se podem mostrar claramente o jogo inconstante da vida e as incontáveis e diversas tarefas da existência, e não com caracteres sólidos e já formados". No que se refere ao posicionamento de Goethe com relação à Revolução Francesa, nas Conversações com Eckermann (4 de janeiro de 1824), há a seguinte manifestação do escritor: "É verdade que eu não poderia ser amigo da Revolução Francesa, pois seus horrores estavam muito próximos de mim e me in- 
dignavam diariamente, de hora em hora, ao passo que não era possível prever suas consequências benéficas. E eu também não podia assistir indiferente à tentativa de trazer para a Alemanha de maneira artificial semelhantes cenas que, na França, eram consequência de uma grande necessidade. Mas nem por isso era amigo de um despotismo arbitrário" (Eckermann, 2016, p.521-2).

\section{Referências}

BAKHTIN, M. Problemas da Poética de Dostoiépski. Trad. Paulo Bezerra. Rio de Janeiro: Forense Universitária, 2010.

ECKERMANN, J. P. Conversações com Goethe nos últimos anos de sua vida: 18231832. São Paulo: Editora Unesp, 2016. p.521-2.

MAZZARI, M. V. Os anos de aprendizado de Wilhelm Meister: "um magnífico arco-íris". Revista Literatura e Sociedade, v.1, n.27, 2018.

A dupla noite das tillias - História e natureza no Fausto de Goethe. São Paulo: Editora 34, 2019.

MORETTI, F. O romance de formação. Trad. Natasha Belfort Palmeira. São Paulo: Todavia, 2020.

Cecilia Marks é mestre e doutora em Letras pelo Departamento de Teoria Literária e Literatura Comparada da Faculdade de Filosofia, Letras e Ciências Humanas da Universidade de São Paulo. Atua como pesquisadora independente e mediadora de leitura. @ - ceciliamarks@uol.com.br / https://orcid.org/0000-0002-9524-3114.

Recebido em 20.5.2020 e aceito em 23.5.2020.

${ }^{\text {I }}$ Universidade de São Paulo, Faculdade de Filosofia, Letras e Ciências Humanas, São Paulo, Brasil. 